\title{
Deformation behaviour of self-compacting concrete under tensile loading
}

Timo Wüstholz $\cdot$ Hans-Wolf Reinhardt

Published online: 20 September 2007

(C) RILEM 2007

\section{Erratum to: Materials and Structures DOI 10.1617/s11527-006-9195-8}

Due to an unfortunate turn of events this article is published on the preceding pages with an erroneous version of Figure $6 \mathrm{~b}$. Please find below the correct Figure $6 \mathrm{~b}$ that should be regarded by the reader as the final version.

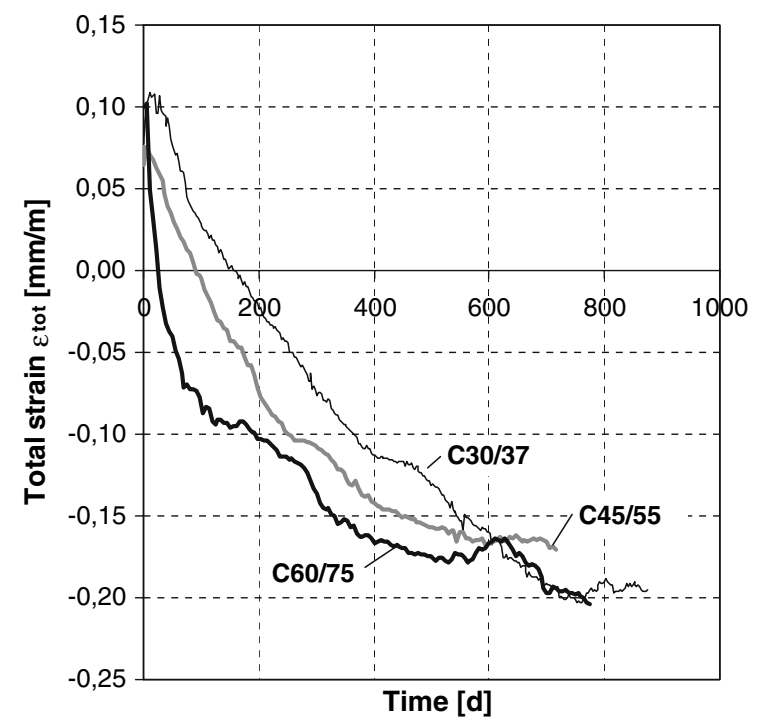

The online version of the original article can be found under doi: $10.1617 / \mathrm{s} 11527-006-9195-8$.

T. Wüstholz $\cdot$ H.-W. Reinhardt $(\bowtie)$

Construction Materials Institute, University of Stuttgart,

Pfaffenwaldring 4, 70550 Stuttgart, Germany

e-mail: reinhardt@iwb.uni-stuttgart.de 